\title{
The Effect of Atmospheric Oxygen on the Puffing and Bursting Phenomena during Vegetable Oils Droplets Vaporization Process for Their Use as Biofuel in Diesel Engine
}

\author{
A. S. Zongo ${ }^{*}$, T. Daho¹, G. Vaitilingom², B. Piriou², J. Valette², C. Caillol ${ }^{3}$, B. G. Segda1, P. Higelin³, \\ J. Koulidiati ${ }^{1}$
}

${ }^{1}$ LPCE, Département de Physique, Université Ouaga 1 Pr JKZ, Ouagadougou, Burkina Faso

${ }^{2}$ Unité de Recherche BioWooEB, CIRAD, Montpellier, France

${ }^{3}$ Laboratoire PRISME, Université d'Orléans, Orléans Cedex 2, France

Email: *zongosaugustin@yahoo.fr

How to cite this paper: Zongo, A.S., Daho, T., Vaitilingom, G., Piriou, B., Valette, J., Caillol, C., Segda, B.G., Higelin, P. and Koulidiati, J. (2018) The Effect of Atmospheric Oxygen on the Puffing and Bursting Phenomena during Vegetable Oils Droplets Vaporization Process for Their Use as Biofuel in Diesel Engine. Energy and Power Engineering, 10, 518-533.

https://doi.org/10.4236/epe.2018.1012033

Received: December 1, 2018

Accepted: December 25, 2018

Published: December 28, 2018

Copyright $\odot 2018$ by authors and Scientific Research Publishing Inc. This work is licensed under the Creative Commons Attribution-NonCommercial International License (CC BY-NC 4.0). http://creativecommons.org/licenses/by-nc/4.0/ (c) (i) (8) Open Access

\begin{abstract}
The past literature on the use of vegetable oils as fuel in diesel engine revealed that utilizing vegetable oil fuels in diesel engines may require property changes in the oil or perhaps, some minor engine modifications or operating changes. This study was conducted to search for the effect of atmospheric oxygen on the puffing and bursting phenomena that occur during vegetable oils droplet vaporization process in their use as fuel in diesel engine. The fiber-suspended droplet technique was used, and the normalized square droplet diameter as well as the temperature evolution vicinity the droplet was analyzed. The results show that puffing and bursting phenomena highly depend on oxygen. In presence of atmospheric oxygen, there is an increase of the puffing and bursting intensity and therefore the evaporation rate of the vegetable oil droplets, but in an inert environment or when the environment is oxygen-depleted puffing and bursting phenomena disappearing and make place of a series of explosions with lower magnitude. The lack of oxygen reduces the thermal degradation, polymerization and oxidation reactions and consequently the vaporization rate of vegetable oils droplets; and could therefore lead to the formation of deposits in the form of polymers. This is unsuitable for their use as a fuel in diesel engines. It can also be concluded that atmospheric oxygen has some positive effects on engine performance and emissions when operating with vegetable oil. These results help to address the challenge for the use of alternative fuels such as non-edible vegetable oils.
\end{abstract}




\section{Keywords}

Puffing, Bursting, Oxygen, Nitrogen, Linseed Oil, Vaporization, Engine, Energy

\section{Introduction}

In recent years, some reasons such as the relative decline in oil prices compared to 2008, have reduced the willingness and enthusiasm for the use of pure vegetable oils (PVO) as a fuel in industrialized countries. However, in most developing countries where access to energy for rural populations is still very limited, the use of vegetable oils as fuel for diesel engines remains an important tool for social and economic development. The reliance of these countries' energy sectors on petroleum products makes the economic sector vulnerable due to the fluctuations in oil prices. The use of vegetable oils as a local fuel in a short circuit of self-consumption has a great economic development advantage regarding to the potential of PVO and their derivative as fuel in diesel engines and burners [1] [2] [3] [4] [5]. However, as it is well known, the direct injection engines that are used in agricultural and road tractors, and many industrial stationary engines without prior modification do not accept PVO. Fuelled with non-esterified vegetable oils, they quickly experience operating problems in long-term engine used [6]. These problems among others are the formation of carbon deposits inside the engine, fuel injector fouling, sticking of piston rings, heavy gum deposits on cylinder walls, and a strong cyclic dispersion that can lead to mechanical difficulties or damages [4] [7] [8] [9] [10].

When they deliver up to half their rated power, these engines have average chamber temperatures below $200^{\circ} \mathrm{C}$. Whereas, most of vegetable oils have a flash point temperature much higher than that of fuel oil. That is why a part of vegetable oil droplets will not vaporize but will stick to the walls causing deposits. So, proposals for technological solutions were developed such as piston modification, bi-fuel kits, exhaust gas recirculation, ... to reach sufficient temperature levels and then prevent deposits formation, or solutions such as transesterification, mixture with lighter oil and heating were used [11]. Nevertheless, the combustion of oil, even when heated, purified and refined, is not completely carried out, resulting in higher losses of power and efficiency and higher $\mathrm{CO}, \mathrm{NO}_{\mathrm{x}}$ and $\mathrm{HC}$ emissions than for diesel fuel [11].

Recent studies have shown that the main disadvantage of vegetable oils is their chemical nature. While diesel fuel has straight or branched chain configurations, composed mostly of saturated hydrocarbons, vegetable oils are predominantly formed by (about 95\%) triglycerides which are also composed of saturated or unsaturated fatty acids. The highest degree of unsaturation makes vegetable oils susceptible to oxidation leading to free radical formation and polymerization [10]. This polymerization can either be an oxidative polymerization in storage, 
or a more complex thermal polymerization occurring at high temperatures and pressures preceding combustion [10]. In the case of vegetable oils, partial distillation is observed with subsequent polymerization of unburned droplets on the combustion chamber faces followed by pyrolysis leading to carbonaceous deposits. Earlier studies like those of Hassett and Hasan, and Engler et al cited by Yahya Azmi Bi [10] reported that vegetable oils tend to polymerize three dimensionally when the unburned oil comes in contact with hot metal surfaces. These polymers when formed were unlikely to burn and then accumulated as deposits on the engine combustion chamber. These phenomena take place mainly during spray formation and vaporization process for certain temperature range [9] [12] [13] [14].

Studies have recently showed that vegetable oil droplets vaporization is associated with puffing and bursting phenomena [15] resulting from the thermal degradation and polymerization of vegetable oils that lead to deposits formation [16]. These studies have also shown the influence of temperature on the occurrence of these phenomena. When the temperature increases, the intensity of these phenomena increases and therefore the evaporation rate of the vegetable oil droplets. However, while the influence of temperature on the phenomena of puffing and bursting is well known, the influence of the nature of the atmosphere remains unknown.

The knowledge of the influence of the environment nature is a key aspect that is worth to be known. Indeed, in a diesel engine, there is generally an excess of air, but considering the mode of diesel combustion (diffusing combustion important for oils, and dead volumes) it is possible to have areas of oxygen deficit, in the same way, anaerobic conditions can also occur in the atomized jet. In these areas the behavior of vegetable oils droplets is important to be qualitatively well known. The contribution of this paper is to investigate the effect of atmospheric oxygen on puffing and bursting that is a part of vegetable oils droplet vaporization process. This has received little attention in the literature on vegetable oils vaporization. It is important since the oxygen is well-known to significantly influence vegetable oils thermal degradation and polymerization, thus understanding these effects would allow the vegetable oils vaporization process in diesel engine to be optimised at the low temperatures conditions where problems are encountered. By this way some engine performance problems such as carbon deposits in combustion chamber and injector coking or filter clogging could be addressed. Further, it gives insight for developing computationally-efficient and accurate simulations of vegetable oils vaporization and combustion. For this purpose linseed oil which is more suitable to polymerization phenomenon that lead to deposits formation were chosen.

\section{Materials and Methods}

The suspended droplet technique was used. The principle of the measurement is as follows: A droplet of vegetable oil is suspended from a quarter fiber of very 
small diameter and low thermal conductivity. The droplet thus suspended is then plunged into a hot air flow or into a heated closed chamber (in this study). The droplet is in a fixed position and can be observed by camera during vaporization or combustion process. A thermocouple is placed in the immediate vicinity of the droplet and follows the temperature evolution in the vicinity of the droplet during the vaporization process. This experimental device can monitor the behavior of liquid fuels droplets vaporization using a speed camera. The data from this monitoring gave qualitative information about the phases of droplets vaporization process and was used to determine quantitative droplets vaporization characteristics such as vaporization rate, vaporization time, etc. The experimental device (Figure 1) consists of three main sets: a closed and unpressurized cubic enclosure, a system of heating, and an acquisition and data processing systems. Figure 1 shows the schematic diagram of experimental setup.

\subsection{The Vaporization Chamber}

It consists of a stainless steel cubic metal enclosure with internal size of $100 \times$ $100 \times 100 \mathrm{~mm}$. Two opposite sides of the enclosure are removable. A porthole was arranged on each removable side to create an optical path between the CCD camera and the LED light source. This allows the measurement of the droplets contours placed in the enclosure by the camera. An isolation system was made inside the chamber with bricks and refractory cement. The enclosure has an air inlet and an output system to renew its internal environment. A system for sweeping the enclosure with nitrogen was also installed for testing in an inert atmosphere. The flow rate can be regulated using a flow meter.

\subsection{Heating Device and Suspension System of the Droplet}

The heating system includes a kanthal resistance and holding plates. The resistance consists of a wire of kanthal of $2 \times 10^{-3} \mathrm{~m}$ diameter electrically isolated using ceramic tubes. The whole is maintained stationary using two others pieces. This assembly form "shuttering" for resistance and also a thermal accumulator storing calories. This system allows the chamber temperatures ranging from room

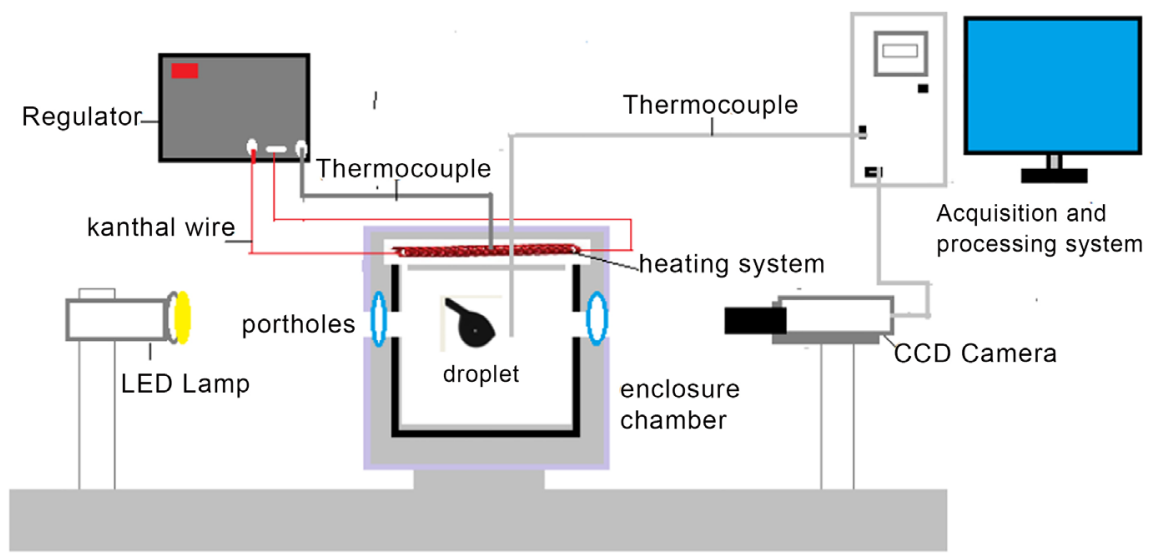

Figure 1. Schematic diagram of experimental setup. 
temperature to a temperature of at least $1023 \mathrm{~K}$. A type K-thermocouple of $10^{-3}$ $\mathrm{m}$ diameter inserted in the middle of the heating system gives its temperature. The control unit is a Pyromat plus 300, equipped with a $230 \mathrm{~V} / 12 \mathrm{~V}$ transformer.

Vegetable oils droplets of diameters ranging from 1 to $1.6 \times 10^{-3} \mathrm{~m}$ are suspended on a quartz fiber (chosen for its low thermal conductivity) with a diameter about $0.4 \times 10^{-3} \mathrm{~m}$. The angle of inclination of the fiber is about $30^{\circ}$ downward from the horizontal to avoid dropping out of the droplet.

\subsection{Measurement and Data Logging System of Temperature}

The temperature in the vicinity of the droplet is measured with a type $\mathrm{K}$ thermocouple of diameter $0.25 \times 10^{-3} \mathrm{~m}$ which is placed at a distance of about $1.6 \times$ $10^{-3} \mathrm{~m}$ of the droplet during the measurement of the projected surface of the droplet. The acquisition of temperature is achieved through a converter that has a "thermocouple" input and a "USB" output. The pressure in the combustion chamber is the atmospheric pressure.

\subsection{Image Acquisition and Data Processing System}

A LED lamp of $1.8 \mathrm{~W}$ illuminates the droplet and creates a contrast that gives a clear picture of the droplet. A CCD (Charge Coupled Device) camera connected to a computer through an IEEE 1314 (FWB-PCIE1X20, 2 ports) was used to record droplets size during vaporization process. The CCD camera used is a monochromatic digital camera SONY type SX90 XCD. Its resolution is 1280 pixels horizontally and 960 pixels vertically. It allows acquisition of $30 \mathrm{fps}$. It is equipped with an optical system composed of three parts: a 0.25 lens, a 0.30 $0.37 \mathrm{~m}$ lens and a 2 multiplier. When the suspended droplet was inserted in the chamber, the time dependence of its size recording was performed by the CCD using a specific software, developed by Vision Alliance for the device. The software extracts the contours of projected surface of the droplet by calculating an ellipse whose perimeter corresponds to the contours of the droplets at each time step (Figure 2): With the inclination of the quartz fiber and the gravity and fiber effects, the droplet has an ellipsoidal shape. The uncertainty in the determination of the projected surface is such that $\Delta \mathrm{d}^{2} / \mathrm{d}^{2}$ is about $3 \%$. The information provided by the camera and thermocouple are recorded via the software.

\subsection{Materials Used}

Linseed oil was used. Linseed oil were purchased in a refined standard state from a reseller in France, Linseed oil fatty acids composition determined by gas chromatography, using a Agilent 6890 GC type with a FID detector and a CP-WAX 58CB column $(25 \mathrm{~m} \times 0.32 \mathrm{~mm} \times 0.2 \mu \mathrm{m})$ are reported in Table 1 . Table 2 gives some fuel properties of linseed oils.

\subsection{Experimental Procedure}

The experimental procedure to study the influence of atmospheric oxygen as 


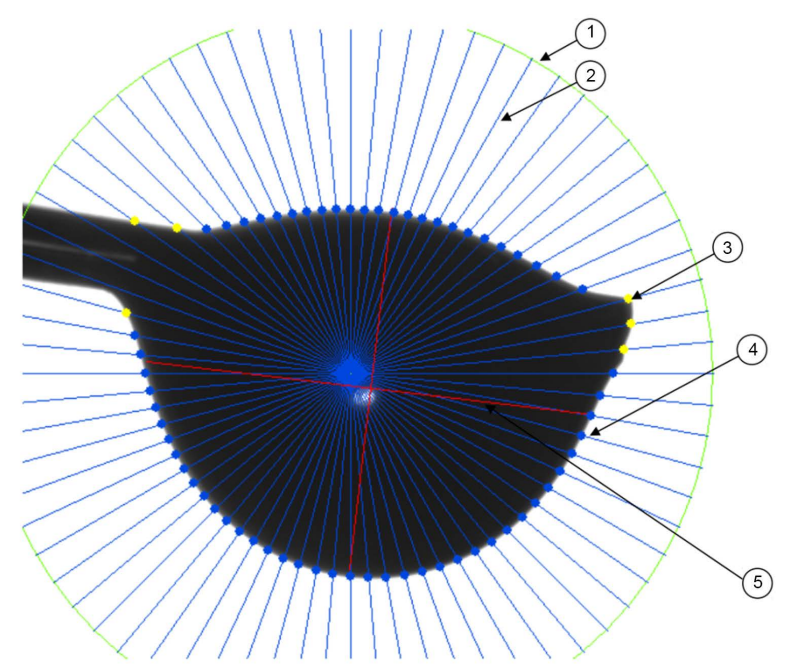

Figure 2. Projected surface determination of the droplet during the vaporization process. 1: Search box, 2: Edge detection Line, 3: Edge detected, 4: The edge used in the calculation of the ellipse, 5: Axes of the calculated ellipse.

Table 1. Linseed oil fatty acids composition (\%).

\begin{tabular}{ccccccc}
\hline Fatty acids & Oleic $(\mathrm{C} 18: 1)$ & $\begin{array}{c}\text { Linoleic } \\
(\mathrm{C} 18: 2)\end{array}$ & $\begin{array}{c}\text { Linolenic } \\
(\mathrm{C} 18: 3)\end{array}$ & $\begin{array}{c}\text { Palmitic } \\
(\mathrm{C} 16: 0)\end{array}$ & $\begin{array}{c}\text { Stearic } \\
(\mathrm{C} 18: 0)\end{array}$ & $\begin{array}{c}\text { Other minor } \\
\text { fatty acids }\end{array}$ \\
\hline Formula & $\mathrm{C}_{18} \mathrm{H}_{34} \mathrm{O}_{2}$ & $\mathrm{C}_{18} \mathrm{H}_{32} \mathrm{O}_{2}$ & $\mathrm{C}_{18} \mathrm{H}_{30} \mathrm{O}_{2}$ & $\mathrm{C}_{16} \mathrm{H}_{32} \mathrm{O}_{2}$ & $\mathrm{C}_{18} \mathrm{H}_{38} \mathrm{O}_{2}$ & - \\
$\%$ & 18.00 & 16.3 & 56.10 & 5.2 & 3.2 & 1.2 \\
\hline
\end{tabular}

Table 2. Some fuel properties of linseed oil used [17].

\begin{tabular}{ccccccc}
\hline & $\begin{array}{c}\text { Density }\left(\mathrm{kg} / \mathrm{m}^{3}\right. \\
\text { at } 288 \mathrm{~K})\end{array}$ & $\begin{array}{c}\text { Kinematic viscosity } \\
\left(\mathrm{mm}^{2} / \mathrm{s} \text { at } 313 \mathrm{~K}\right)\end{array}$ & $\begin{array}{c}\text { Flash } \\
\text { point }(\mathrm{K})\end{array}$ & $\begin{array}{c}\text { high heating } \\
\text { value }(\mathrm{MJ} / \mathrm{kg})\end{array}$ & $\begin{array}{c}\text { Carbon } \\
\text { residue }(\%)\end{array}$ & $\begin{array}{c}\text { Iodine } \\
\text { value } \mathrm{gI}_{2} / \mathrm{g}\end{array}$ \\
\hline Linseed oil & 924 & $26-27^{\mathrm{a}}$ & 514 & $39.3-39.5$ & 0.22 & 180 \\
\hline
\end{tabular}

at $310.8 \mathrm{~K}$, bat $313 \mathrm{~K}$.

shown in Figure 3. The puffing and bursting phenomena take place in the temperature range of 683 to $723 \mathrm{~K}$ with linseed oil droplet. A system for sweeping was also installed and allows to sweep the enclosure with nitrogen or air or air depleted in oxygen. The flow rate can be regulated using a flow meter, then tests were conducted at the temperature of $703 \mathrm{~K}$, under atmospheric pressure and under three different environment in the same conditions. These are:

- Under oxidizing atmosphere by sweeping the enclosed enclosure by air at a flow rate of $1 \mathrm{~L} / \mathrm{mn}$. This flow rate of $1 \mathrm{~L} / \mathrm{mn}$ corresponds to the flow rate at which a stable temperature of $703 \mathrm{~K}^{\circ} \mathrm{C}$ is obtained in the closed chamber.

- Under inert atmosphere, obtained by sweeping the enclosed enclosure with nitrogen at a flow rate of $1 \mathrm{~L} / \mathrm{mn}$.

- Under air depleted in oxygen (5\% oxygen) obtained by sweeping the enclosed enclosure by air depleted in oxygen at a flow rate of $1 \mathrm{~L} / \mathrm{mn}$.

The temperature in the chamber was first stabilized. Then one microliter of 


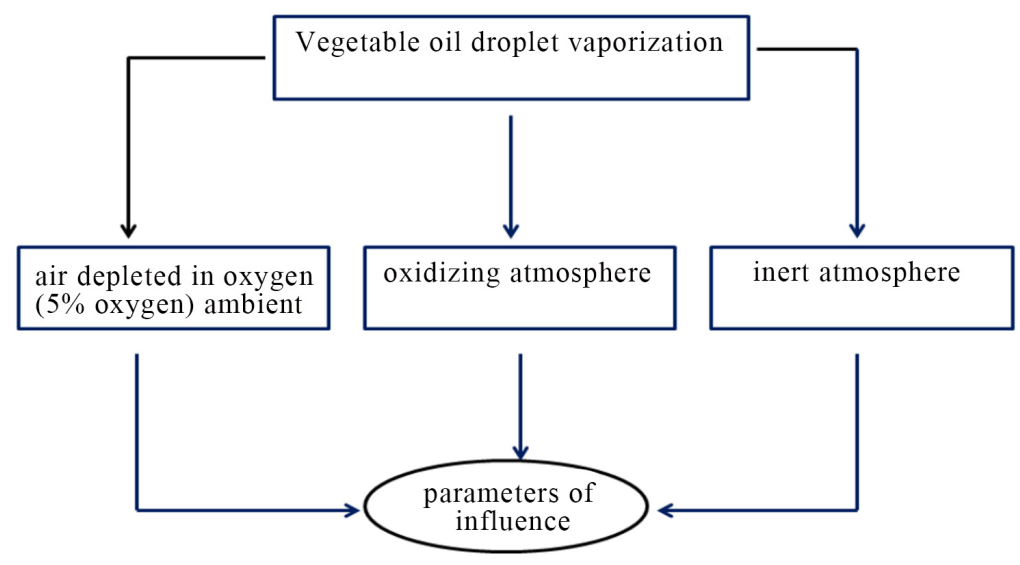

Figure 3. Chart of oxygen influence on puffing and bursting verification process.

linseed oil was dropped carefully on the quartz fiber, outside the chamber, using a micro syringe of 10 microliters. The droplet thus suspended was introduced into the chamber by a sliding rod on which was fixed the quartz fiber. The acquisition can be manually or automatically triggered once the droplet was introduced. For the same sample, tests were conducted at least five times to check repeatability of measurements before moving on to another sample or other operating conditions. The processing of the data then allowed obtaining and analyzing parameters such as the temperature in the vicinity of the droplet, the evolution of the normalized square droplet diameter versus the normalized time.

\section{Uncertainties}

The uncertainties on the determination of projected surface and the vaporization rate were estimated by using Equation (1)-(3) below:

$$
\begin{aligned}
& \delta x=\sqrt{\frac{1}{n} X_{\text {exp }}} \\
& \text { With } X_{\text {exp }}=\sqrt{\frac{1}{n-1} \sum_{i=1}^{n}\left(x_{i}-\bar{x}\right) 2} \\
& \text { And } \bar{x}=\frac{1}{n} \sum_{i=1}^{n} x_{i}
\end{aligned}
$$

Ten consecutive images of projected surfaces were considered. For linseed oil the uncertainty is $2 \%$ for the projected surface and $0.01 \%$ for the determination of the vaporization constants.

$x_{i}: i$ the value, obtained over a series of measurements of a sample, $\bar{x}$ is averaged value of $x_{j} ; x$ : average value, on the series of n measures; $n$; number of measures; $X_{\text {exp }}$ : experimental value, $\delta_{x}$ is uncertainty on the determination.

\section{Results and Discussion}

\subsection{Puffing and Bursting Phenomema and the Ambiant Temperature Influence}

Figure 4 shows the curve evolution of the normalized square diameter versus the 


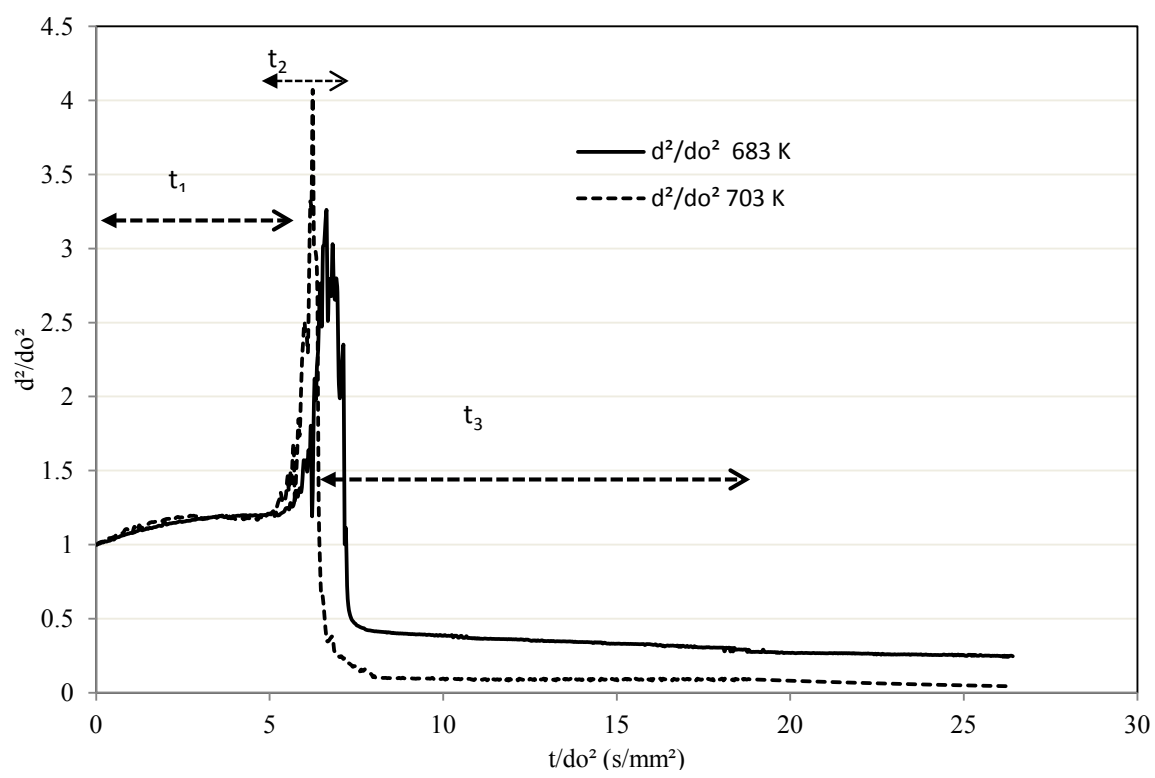

Figure 4. Curve evolution of the normalized square diameter versus the normalized time at the ambient temperatures of $683 \mathrm{~K}$ and $703 \mathrm{~K}$.

normalized time at the ambient temperatures of $683 \mathrm{~K}$ and $703 \mathrm{~K}$. Curves show the phenomena of puffing and bursting that occurs during the vaporization process of linseed oil droplets. The two curves all present the same characteristics showing the three classical phases of the vaporization of vegetable oil droplets observed and described in previous studies: 1) the transient heating phase $t_{1}, 2$ ) the fluctuation evaporation phase $t_{2}$; and 3 ) the residue deposition phase $t_{3}$.

The transient heating phase so called heating and expansion phase is the duration when the normalized square diameter of the droplet reaches from 1 to a maximum, the fluctuation evaporation phase is defined as the duration when the curve appears obvious fluctuation, the last phase is the residue deposition phase or vaporization end phase. This last phase of residue deposition gives an approximation of the amount of residue formed on the fiber: the closer the normalized square diameter curve is to the abscissa axis, the less residue there is on the fiber.

As expected, it can be seen that, even if the both curves have same caracteristic, the increase in temperature ambient shortened the transient heating phase and the fluctuation evaporation phases, increased the intensity of puffing and bursting, decresed the size of the residues on the fiber. The values are given in Table 3.

The time of the heating and expansion phase of the droplet is shortened by the effect of the increase in the ambient temperature because the phenomena of thermal degradation and mass and heat transfer that take place during this phase are accelerate under the effect of the increase in heat. Similarly, the shortening of the fluctuation phase time can be explained by the fact that under the effect of the increase in temperature, oxidation reactions and the others multiple complex reactions that produce gaseous or volatile products become more significant and 
Table 3. Vaporization caracteristic of linseed droplet at ambient temperature of 683 and $703 \mathrm{~K}$.

\begin{tabular}{ccccc}
\hline Temperature (K) & $\begin{array}{c}\text { Transient heating } \\
\text { phase }\left(\mathrm{s} / \mathrm{mm}^{2}\right)\end{array}$ & $\begin{array}{c}\text { Fluctuation phase } \\
\left(\mathrm{s} / \mathrm{mm}^{2}\right)\end{array}$ & $\begin{array}{c}\text { Intensity of } \\
\text { bursting }\left(\mathrm{d}^{2} / \mathrm{do}^{2}\right. \\
\text { peak height })\end{array}$ & $\begin{array}{c}\text { Size of fiber on } \\
\text { residues phase } \\
\left(\mathrm{d}^{2} / \mathrm{do}^{2}\right)\end{array}$ \\
\hline 683 & 5.03 & 1.57 & 3.25 & 0.25 \\
703 & 4.48 & 1.1 & 4.07 & 0.052 \\
\hline
\end{tabular}

occur simultaneously, which release in a very short time the gaseous products in large quantities that escape and thus increasing the intensity puffing and bursting. The decrease in the size of the residues on the fibre is due to the increase in exothermic reactions caused by the increase in temperature, which has the advantage of producing more gaseous and volatile products and therefore less polymers and solid products that are deposited on the fiber.

Figure 5 shows a series of photographs of linseed oil droplet vaporization process at the ambient temperature of $703 \mathrm{~K}$, which show in images transient heating phase, fluctuation evaporation phase and residue deposition phase. During the period from $0.000 \mathrm{~s} / \mathrm{mm}^{2}$ to $3.41 \mathrm{~s} / \mathrm{mm}^{2}$, it is not observed no obvious bubbles inside the droplet which grows only in volume. From $\mathrm{t} / \mathrm{do}^{2}=$ $4.30 \mathrm{~s} / \mathrm{mm}^{2}$ bubbles begin to form inside the droplet causing the droplet to puff. Puffing and bursting phenomena become noticeable from $\mathrm{t} / \mathrm{do}^{2}=6.18 \mathrm{~s} / \mathrm{mm}^{2}$.

Figure 6 shows the evolution of temperature in the vicinty of droplet versus normalized time at ambient temperatures of $683 \mathrm{~K}$ and $703 \mathrm{~K}$. The both curves have the same characteristics. There are essentially three phases corresponding to the three classic phases of vegetable oils droplets vaporization. During the transient heating phase temperature curve increases gradualy and then suddenly peak during the fluctuation phase, it continues with a stable phase during the residue deposition phase. The gradual increase of temperature in the vicinity of the droplet during the transient heating phase can be attributed to the oxidation at the droplet surface and the escape of the first components that have reached their vaporization temperature and are vaporizing. The peak obsereved corresponds to the ejection of hot gases by the bursting of the droplet. When the temperature increases, the intensity of the explosions increases, thus the volume of the gases, which shows that the temperature curve at $703 \mathrm{~K}$ has a higher peak $(1084 \mathrm{~K})$ than that of $683 \mathrm{~K}(727 \mathrm{~K})$ i.e. a $\Delta \mathrm{T}=381 \mathrm{~K}$ at $703 \mathrm{~K}$ versus $\Delta \mathrm{T}=44 \mathrm{~K}$ at $683 \mathrm{~K}$.

\subsection{Effect of Atomospheric Oxygen on Puffing and Bursting Phenomena}

The normalized square diameter versus the normalized time curve of the linseed oil droplet in the different environments for an ambient temperature of $703 \mathrm{~K}$ are shown in Figure 6.

For the oxidizing environment under air sweeping at a flow rate of $1 \mathrm{l} / \mathrm{min}$, the normalized square diameter evolution curve presents the classical characteristics including the three vaporization phases mentioned (Figure 7). 


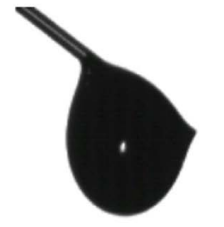

$\mathrm{t} / \mathrm{do}^{2}=0.00 \mathrm{~s} / \mathrm{mm}^{2}$

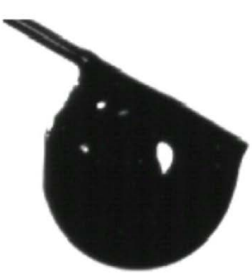

$4.30 \mathrm{~s} / \mathrm{mm}^{2}$

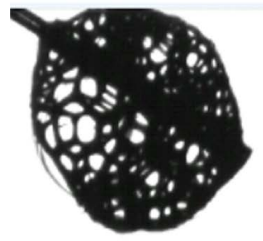

$6.32 \mathrm{~s} / \mathrm{mm}^{2}$

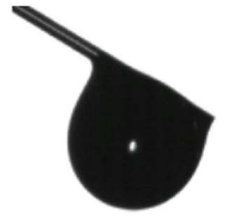

$2.02 \mathrm{~s} / \mathrm{mm}^{2}$

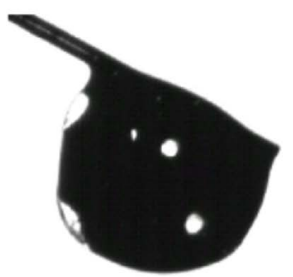

$4.93 \mathrm{~s} / \mathrm{mm}^{2}$

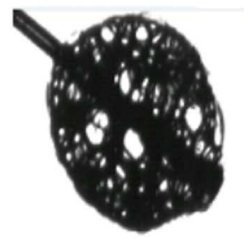

$6.52 \mathrm{~s} / \mathrm{mm}^{2}$

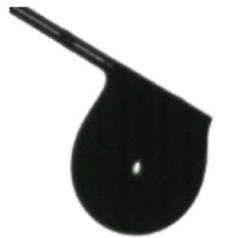

$3.41 \mathrm{~s} / \mathrm{mm}^{2}$

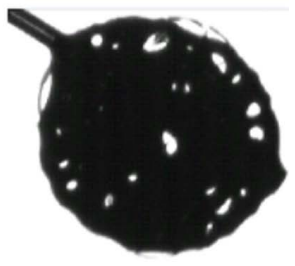

$6.18 \mathrm{~s} / \mathrm{mm}^{2}$

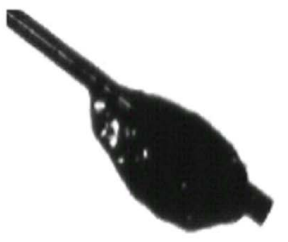

$8.17 \mathrm{~s} / \mathrm{mm}^{2}$

Figure 5. Series of photographs of linseed oil droplet vaporization process at the ambient temperature of $703 \mathrm{~K}$ under oxidative ambient.

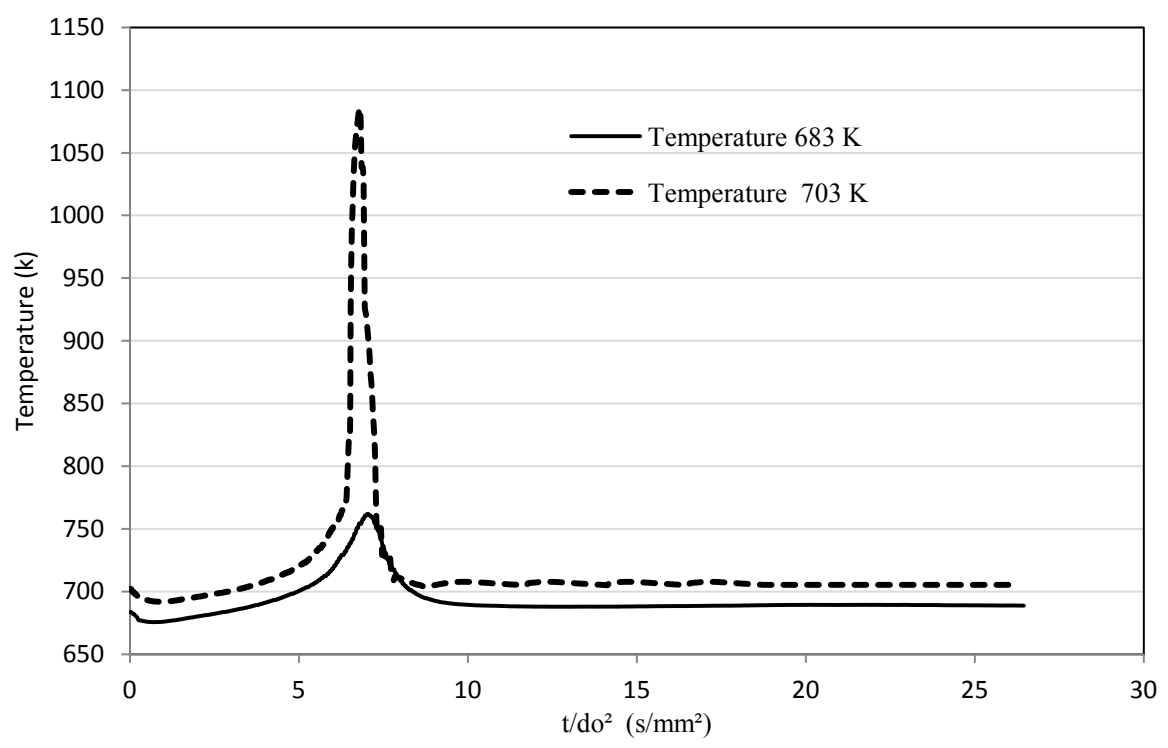

Figure 6. Evolution of temperature curve in the vicinty of droplet versus normalized time at $683 \mathrm{~K}$ and $703 \mathrm{~K}$.

For nitrogen and air depleted in oxygen environments, the normalized square diameter evolution curves show different characteristics from the previous environment: the heating phase was always observed but after this phase, the fluctuation phase has disappeared. Instead of puffing and burstings, it was observed a series of explosions with lower magnitude compared to those obtained 


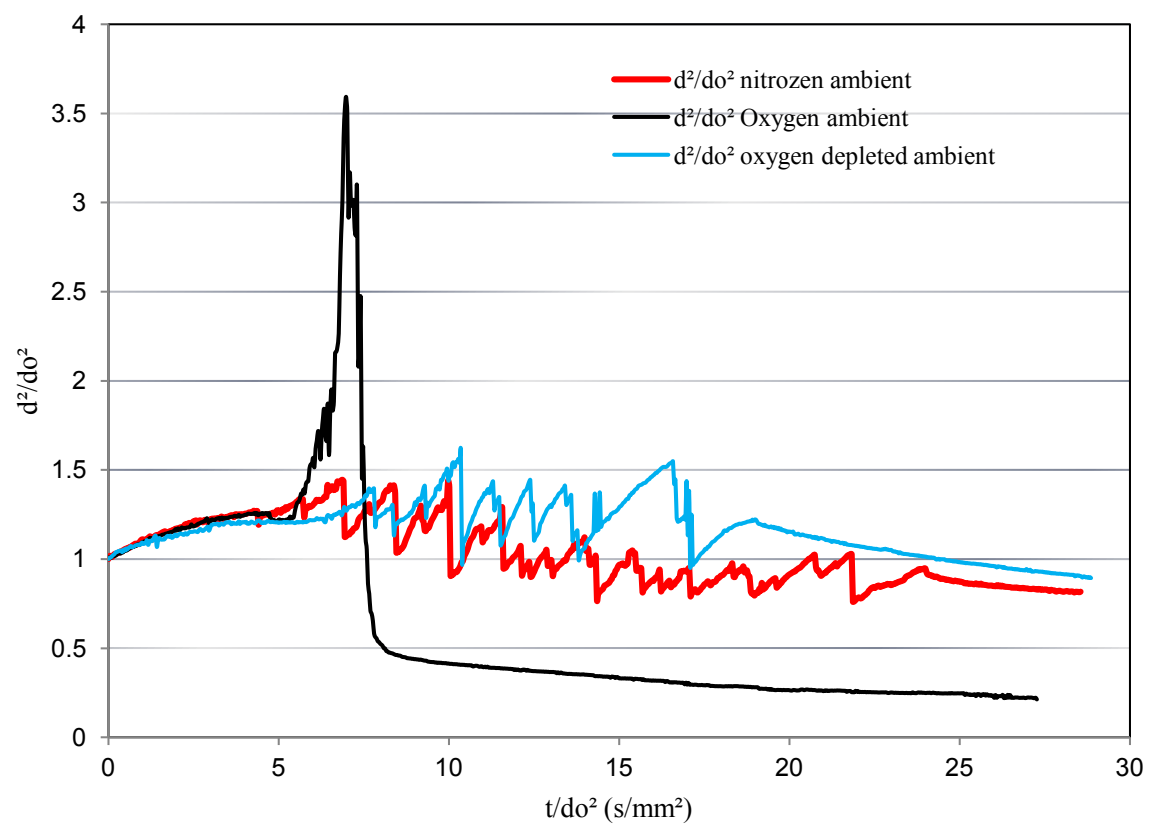

Figure 7. Effect of atmospheric oxygen on puffing and Bursting phenomena at ambient temperature of $703 \mathrm{~K}$.

in an oxidizing environment. This disappearance of burstings can be attributed to the absence of ejection of hot gaseous compounds resulting from reactions observed in an oxidizing environment. But the presence of series of microexplosions indicates that there is always a low gas emission, thus hot gases realese in low quantity. This fact is confirmed by the temperature evolution curves (see Figure 8) in the vicinity of the droplet which don't indicate a significant variation of the temperature: it remains almost constant, indicating that there is no heat release percieved by the thermocouple. Figure 9 shows the disappearance of explosions in an inert atmosphere and the appearance of low intensity micro-explosions. On the pictures it can be observed that bubbles obvious have disappeared but gases are only trapped in the droplet which increases in it global volume. The release of hot gases and their abundance is therefore only related to the presence of oxygen, which thus seems to be a favorable factor for the thermal decomposition of triglycerides and the formation of new products resulting from other secondary reactions like oxidation.

The presence of small bubbles and micro-explosions in inert environment indicates that there are always gases that are formed inside the droplet in lower quantity. These gases most probably come from the thermal degradation of triglyceride molecules in the absence of oxygen (pyrolysis). Indeed, previous studies conducted on the pyrolysis of vegetable oils by many researchers [18] [19] [20] [21] have shown that there is formation of products such as alkanes, alkenes, dienes, aromatic compounds and carboxylic acids with carbon numbers ranging from 4 to 20 , and other unsaturated compounds which are difficult to identify [20]. In addition, the same studies have demonstrated that the nature of compounds and their abundance were highly depend on the temperature and 


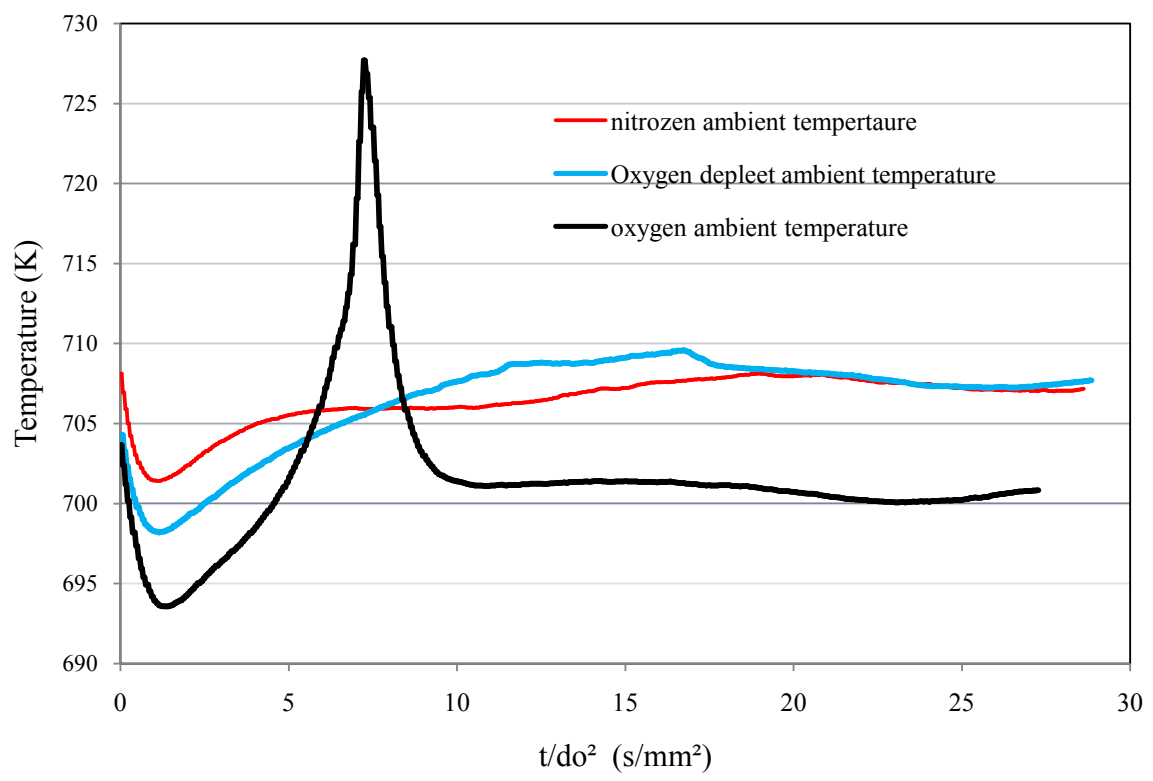

Figure 8. Effect of atmospheric oxygen on temperature viscinty the droplet evolution at ambient temperature of $703 \mathrm{~K}$.
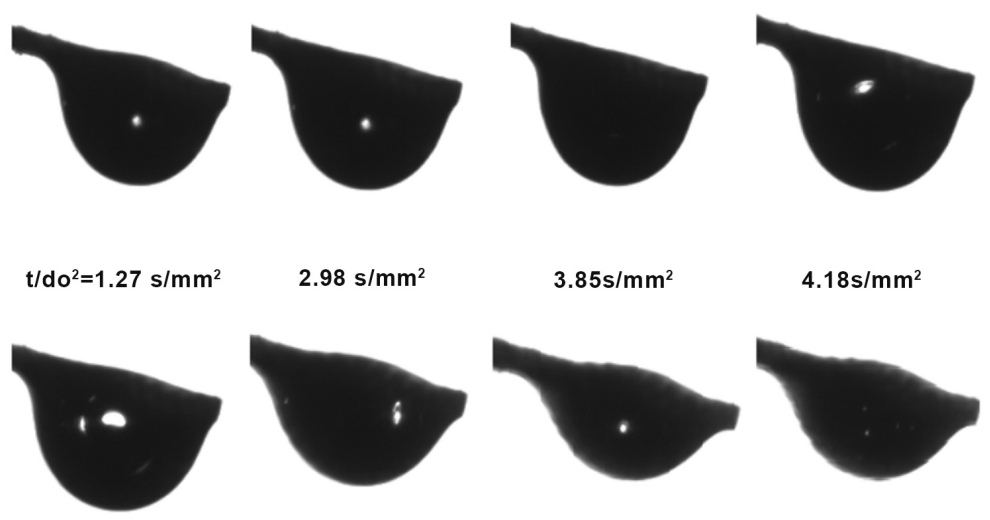

$2.98 \mathrm{~s} / \mathrm{mm}^{2}$

$3.85 \mathrm{~s} / \mathrm{mm}^{2}$

$4.18 \mathrm{~s} / \mathrm{mm}^{2}$

$5.10 \mathrm{~s} / \mathrm{mm}^{2}$
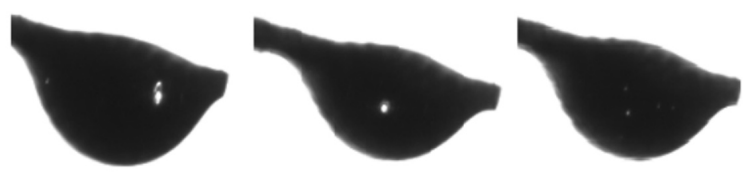

$6.82 \mathrm{~s} / \mathrm{mm}^{2}$

$8.46 \mathrm{~s} / \mathrm{mm}^{2}$

$9.75 \mathrm{~s} / \mathrm{mm}^{2}$
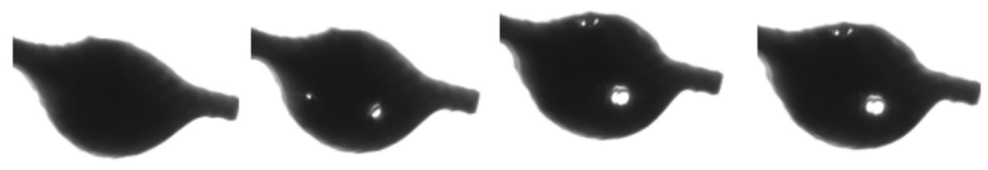

$11.95 \mathrm{~s} / \mathrm{mm}^{2}$

$12.93 \mathrm{~s} / \mathrm{mm}^{2}$

$16.30 \mathrm{~s} / \mathrm{mm}^{2}$

$17.47 \mathrm{~s} / \mathrm{mm}^{2}$

Figure 9. Series of photographs of linseed oil droplet vaporization process showing micro-explosions at the ambient temperature of $703 \mathrm{~K}$ under inert ambient.

the operating parameters because of the complexity of the mechanism of thermal decomposition and the occurrence of numerous chemical reactions [20].

Furthermore, V.P. Doronin et al. [22] investigated catalytic cracking of vegetable oils and indicated that vegetable oils thermolic reaction in absence of oxygen required high temperature to decompose saturated fatty acids to form 
alkanes, fatty acids, ketones, esters, diacylglycerides, etc. They have shown that dimeric compounds appeared to be the main derivatives as a result of thermolytic reactions of unsaturated fatty acids and that dimerization and polymerization of unsaturated fatty acids is reported to take place via Diel-Alder type reactions.

In addition, it is very likely that some compounds produced in the both environments (inert and oxidative) be identical. Indeed, V.P. Doronin et al. [22] reported that in the presence of oxygen, oxidative and nonoxidative reactions will occur simultaneously. On another note, even in inert ambient, there are molecular oxygen that are chemically bounded in triglyceride or oxygen-containing radicals (like $\mathrm{OH}, \mathrm{O}$ ) in vegetable oils. These molecular are an additional source of oxygen other than atmospheric oxygen present in air. When sufficient oxygen is not available, the components from thermal degradation will react with these molecular oxygen and eventually lead to the formation of gaseous or oxidative products. The gases and other residual products resulting from this thermal degradation are probably similar to those resulting from the pyrolysis of vegetable oils in the same temperature ranges.

The abundance of gaseous products in an oxygen atmosphere can also be explained by the fact that in the oxidative environment, in addition to the thermal degradation reactions that occur under the effect of temperature, there are also oxidation reactions in which not only the products resulting from thermal degradation are involved, but also the minority compounds present in the oil. This oxidation therefore releases many gaseous products, and heat which contributes in turn to the above-mentioned thermal degradation and thus reduces the formation of polymers.

The effect of oxygen is also seen in the residues deposition phasef. By comparing the curves in an inert environment and in an oxidizing environment, the residues on the fiber at the end of vaporization in oxygen atmosphere are sufficiently lower than those in nitrogen or air depleted in oxygen atmosphere. Compared to literature on vegetable oils polymerization [23] this trend of increasing residues in nitrogen atmosphere can be explained by the fact that vegetable oil thermal polymerization under an oxygen-deficient environment is carried out according to a Diels-Alder mechanism or according to a radical mechanism leading more to the formation of non-gaseous and non-volatile compounds. While in an oxygen environment vegetable oils thermal oxidative polymerization occur according a radical mechanism leading mainly to the formation of gaseous and volatile compounds. These gaseous compounds are released directly, while the volatile compounds reach their vaporization temperature and volatilize, thus increasing the volume of the gases. Therefore, atmospheric oxygen from the air is a very important factor, like temperature, in the thermal degradation and vaporization of vegetable oil droplets. It significantly contribute to the increasing the vaporization rate of vegetable oils and could reduce the polymer formation that leads to the formation of deposits in the combustion chamber of diesel engines when vegetable oils are used as fuel. 


\section{Conclusion}

The use of pure vegetable oils as a local fuel in a short circuit of self-consumption has a great economic development advantage for these countries. The sensitivity of oxygen atmospheric to puffing and bursting phenomena that occur during vegetable oils vaporization process has been investigated in this paper. It was found that puffing and bursting phenomena is highly dependent on the nature of the ambient (inert or oxidative). In the same temperature, puffing and bursting phenomena occur with high frequency, intensity and amplitude in oxidizing ambient while in inert ambient puffing and bursting desapperance making place to micro-explosion with lower magnitude. Vegetable oils possess, in addition to their potentially reactive sites (unsaturation and ester functions), other functional groups depending on the nature of the oil, which make the oils subject to multiple chemical reactions in presence of oxygen. When oxygen depleted or in an inert ambient, all the reactions that involved oxygen from the air disappear, only pyrolysis reactions still take place, thus reducing the production of gaseous and volatils compounds. Atmospheric oxygen from the air is a very important factor, like temperature, in the thermal degradation and vaporization of vegetable oil droplets. It significantly contribute to increasing the vaporization rate of vegetable oils and could reduce the polymer formation that leads to the formation of deposits in the combustion chamber of diesel engines when vegetable oils are used as fuel. This study has highlighted the crucial importance of atmospheric oxygen in the combustion of vegetable oils in diesel engines. Experimental studies for more detailed identification of compounds resulting from thermal degradation of vegetable oils in inert or oxydizing ambient is scientific issus worthly to be investigate and will serve as a basis for the establishment of reaction mechanisms for vegetable oils combustion in disiel ingine combustion chamber.

\section{Acknowledgements}

A.S. Zongo would like to thank the French Cooperation in Burkina Faso who, through the Service for Cooperation and Cultural Action (SCAC), financed this study by awarding an internship fellowship in 2017 at CIRAD Montpellier

\section{Conflicts of Interest}

The authors declare no conflicts of interest regarding the publication of this paper.

\section{References}

[1] Altin, R., Cetinkaya, S. and Yücesu, H.S. (2001) The Potential of Using Vegetable Oil Fuels as Fuel for Diesel Engines. Energy Conversion and Management, 42, 529-538. https://doi.org/10.1016/S0196-8904(00)00080-7

[2] Ramadhas, A.S., Jayaraj, S. and Muraleedharan, C. (2004) Use of Vegetable Oils as I.C. Engine Fuels-A Review. Renewable Energy, 29, 727-742. 
https://doi.org/10.1016/j.renene.2003.09.008

[3] Natarajan, R., Karthikeyan, N.S., Avinash, A. and Sathiyanarayanan, K. (2008) Use of Vegetable Oil as Fuel to Improve the Efficiency of Cooking Stove. Renewable Energy, 33, 2423-2427. https://doi.org/10.1016/j.renene.2008.01.022

[4] Chiaramonti, D., Rizzo, A.M., Spadi, A., Prussi, M., Riccio, G. and Martelli, F. (2013) Exhaust Emissions from Liquid Fuel Micro Gas Turbine Fed with Diesel Oil, Biodiesel and Vegetable Oil. Applied Energy, 101, 349-356.

https://doi.org/10.1016/j.apenergy.2012.01.066

[5] Varuvel, E.G., Mrad, N., Tazerout, M. and Aloui, F. (2012) Experimental Analysis of Biofuel as an Alternative Fuel for Diesel Engines. Applied Energy, 94, 224-231. https://doi.org/10.1016/j.apenergy.2012.01.067

[6] Mwangi, J.K., Lee, W.-J., Chang, Y.-C., Chen, C.-Y. and Wang, L.-C. (2015) An Overview: Energy Saving and Pollution Reduction by Using Green Fuel Blends in Diesel Engines. Applied Energy, 159, 214-236. https://doi.org/10.1016/j.apenergy.2015.08.084

[7] Tyan III, T.W., Dodge, L.G. and Callahan, T.J. (1984) The Effects of Vegetable Oils Properties on Injection and Combustion in Two Different Diesel Engines. JAOCS, 61, 1610-1619. https://doi.org/10.1007/BF02541645

[8] Peterson, C.L., Wagner, G.L. and Auld, D.L. (1983) Vegetable Oil Substitutes for Diesel Fuels. Transactions of the American Society of Agricultural Engineers, 322327. https://doi.org/10.13031/2013.33929

[9] Hassan, M.H. and Salit, M.S. (1993) Boifuel as Diesel Fuel Alternative: An Overview Journal of Energy. Heat and Mass Transfert, 15, 293-304.

[10] Yahya, A.B. (1988) Performance Characteristics of a Direct Injection Diesel Engine Operating on Methyl Soyoil and Methyl Tallow Esters. Retrospective Teses and Dissertations, 8815.

[11] Hazar, H. and Aydin, H. (2010) Performance and Emission Evaluation of a CI Engine Fueled with Preheated Raw Rapeseed Oil (RRO)-Diesel Blends. Applied Energy, 87, 786-790. https://doi.org/10.1016/j.apenergy.2009.05.021

[12] Knothe, G., Bagby, M.O., Ryan, T.W. and Challahan, T.J. (1991) Degradation of Unsaturated Triglycerides Injected into a Pressurized Reactor. JAOCS, 68, 259-264. https://doi.org/10.1007/BF02657621

[13] Knothe, G., Bagby, M.O., Ryan, T.W. and Challahan, T.J. (1992) Semi-Volatile and Volatile Compounds Formed by Degradation of Triglycerides in a Pressurized Reactor. JAOCS, 69, 341-346. https://doi.org/10.1007/BF02636064

[14] Pramanik, K. (2003) Properties and Use of Jatropha Curcas Oil and Diesel Fuel Blends in Compression Ignition Engine. Renewable Energy, 28, 239-248. https://doi.org/10.1016/S0960-1481(02)00027-7

[15] Wang, J., Wang, X., Chen, H., Jin, Z. and Xiang, K. (2018) Expreimental Study on Puffing and Evaporation Characteristics of Jatropha Straight Vegetable Oil (SVO) Droplets. International Journal of Heat Mass Transfer, 119, 392-399. https://doi.org/10.1016/j.ijheatmasstransfer.2017.11.130

[16] Zongo, A.S. (2015) Etude des processus physiques et chimiques mis en jeu lors de la combustion des huiles végétales pures dans les moteurs diesel: Mécanismes de décomposition et de polymérisation. Ph.D. Thesis, Ouaga I Pr Joseph KI-ZERBO, Burkina Faso.

[17] Blin, J., Mouras, S., Sidibe, S.S., Girard, P., Vaitilingom, G. and Pechine, B. (2014) Guide technique pour l'utilisation d'huile végétale carburant dans les moteurs diésel stationnaires. Burkina Faso. 
[18] Xu, J.M., Jiang, J.C., Lu, Y.J. and Chen, J. (2009) Liquid Hydrocarbon Fuels Obtained by the Pyrolysis of Soybean Oils. Bioresource Technology, 100, 4867-4870. https://doi.org/10.1016/j.biortech.2009.04.055

[19] Phung, T.K., Casazza, A.A., Perego, P., Capranica, P. and Busca, G. (2015) Catalytic Pyrolysis of Vegetable Oils to Biofuels: Catalyst Functionalities and the Role of Ketonization on the Oxygenate Paths. Fuel Processing Technology, 140, 119-124. https://doi.org/10.1016/j.fuproc.2015.08.042

[20] Trabelsi, A.B.H., Zaafouri, K., Baghdadi, W., Naoui, S. and Ouerghi, A. (2018) Second Generation Biofuels Production from Waste Cooking Oil via Pyrolysis Process. Renewable Energy, 126, 888-896.

https://doi.org/10.1016/j.renene.2018.04.002

[21] Doronin, V.P., Potapenko, O.V., Lipin, P.V. and Sorokina, T.P. (2013) Catalytic Cracking of Vegetable Oils and Vacuum Gas Oil. Fuel, 106, 757-765.

https://doi.org/10.1016/j.fuel.2012.11.027

[22] Issariyakul, T. and Dalai, A.K. (2014) Biodiesel from Vegetable Oils. Renewable and Sustainable Energy Reviews, 31, 446-471. https://doi.org/10.1016/j.rser.2013.11.001

[23] Korus, R.A., Mousetis, T.L. and Lloyd, L. (1982) Polymérization of Vegetables Oils. Proceedings of the International Conference on Plant and Vegetable Oils as Fuels. 